\title{
Kadın Cinayetleri Konusunda Nedensel Bir Değerlendirme: Sahip Olma Güdüsü
}

\section{A Causal Evaluation on The Issue of Femicide: The Instinct of Possession}

\author{
Şahide Güliz Kolburan \\ Ístanbul Aydın Üniversitesi, Psikoloji Bölümü, İstanbul
}

\section{Özet}

Ülkemizde giderek artan bir gündem oluşturan kadın cinayetleri sahip olma olgusu üzerinden araştırılmaya çalıșılmıştır. Toplumsal cinsiyet kadınlık ve erkeklik algısı o toplum içinde konum rol ve görevlerin belirlenmesi açısından önemlidir. Çalışmada toplumsal cinsiyet algısından hareketle ortaya çıktığı düşünülen “sahip olma duygusu”, Fromm'un “olmak" ve "sahip olmak" kavramları ile açıklanmaya çalışılmıştır.

Bu gözden geçirme çalışmasında kadın cinayetleri ve nedenleri konusunda yazılmış makale, kitap ve tezlerden, istatistik veriler için de Kadın Cinayetlerini Durduracağız Platformu'nun 2017 yılına ilişkin verilerinden yararlanılmıştır.

Fromm'un "olmak" kavramı insancıl ve varoluşçu kuramlarda da "kendini gerçekleştirme" olarak karşıllığını bulmaktadır. İnsancıl kuramlarda kendini gerçekleştirme, psikolojik olarak tam sağlıklı insanı tanımlar. Fromm, "sahip olmayı" ise, sahip olunanı ele geçirmek, üzerinde hakimiyet kurmak ve dilediği şekilde kullanma hakkı olarak tanımlamaktadır. "Sahip olma", ne pahasına olursa olsun, onun korunmasını da beraberinde getirdiğinden, sahip olunan nesnenin kaybedilmesi kişilik bütünlüğü için bir tehdit olarak algılanmaktadır.

Çalı̧smalar genellikle, erkeklerin otoritelerine veya statülerine yönelik tehdit algıladıkları zaman şiddete başvurduklarını göstermektedir. Eril otorite erkeğin benliğini oluşturan temel öğe olarak algılanmaktaysa, karşı gelinmesi tamamen benliğe yapılmış bir saldırı olarak algılanmaktadır.

Kadının sahip olunan bir nesne olarak algılanması, onu dilediği gibi kullanma ve gerektiğinde de ortadan kaldırma hakkını beraberinde getirmektedir. Bu toplumsal algının değişmesinde uzun süreli ve sistemli planlanan "olmak" temelli eğitimler önemlidir.

bireylerin namusun cinsiyet algısına odaklanması yerine; bireye sayg1, kadın-erkek eşitliği ve evrensel dürüstlük, doğruluk olgularına odaklanması sağlanmalıdır. Namus olgusunun bireyin kendisine ait bir değer olduğu vurgulanmalıdır. Nesneye sahip olmak ve birey olmak arasındaki ilişkiyi değerlendirebilme konusunda farkındalık kazandırıcı etkinlikler, çalışmalar ve programlar planlanmalıdır.

Anahtar Kelimeler: Kadın Cinayetleri; Sahip Olma Güdüsü; Toplumsal Cinsiyet.

\begin{abstract}
Femicide that is an increasingly agenda in our country has been tried to be investigated through the fact of having. The perception of gender, femininity and masculinity is important in terms of determining the positions, roles and duties in community. In this study, "the sense of having" which is thought to have emerged from the perception of gender, has been tried to be explained by Fromm's concepts of "to be" and "to have".

For this study scholarly articles, books and dissertations about femicide and its leading factors as well as statistical results of 2017 from "We Will Stop Femicide Platform" have been reviewed.

Fromm's concept of "to be" finds itself as "self-realization" in Humanistic/ Existentialist theories. Self-realization in humanistic theories defines a psychologically healthy person. Fromm defines "having" as to take possession, to dominate on it and to have right to use it. Since "having" brings with it its protection at any cost, the loss of possessed object is perceived as a threat to integrity of personality.

Studies often show that men resort to violence when they perceive threats to their authorities or statutes. If the masculine authority is perceived as the basic element of the man's self, the opposition is perceived totally as an attack to the self

The perception of a woman as a possessed object brings with it the right to use her as he wishes and the right to kill her when necessary. It is important to have long-term and systematically planned "being" based trainings in the change of this social perception.
\end{abstract}

As a result; instead of focusing on the pudicity perception of sex, individuals must be provided to focus on the facts of respect, the equality of woman and man, universal honesty and truthfulness. It should be emphasized that the fact of pudicity is the individual's own values. Awareness-raising activities, studies and programs should be planned to evaluate the relationship between having an object and becoming an individual.

Keywords: Femicide; The Instinct of Possession; Gender.

Sorumlu Yazar: Yrd. Doç. Dr. Şahide Güliz Kolburan* İstanbul Aydın Üniversitesi Psikoloji Bölümü, İstanbul E-mail: sahidegulizkolburan@aydin.edu.tr

${ }^{*}$ Çalışmanın bir bölümü 23-25 Mart 2017 tarihleri arasında İstanbul MEF Üniversitesinde gerçekleștirilen 2. Ulusal Şiddeti Anlamak Kongresinnde sözlü bildiri olarak sunulmuştur.

Geliş:09.03.2017 Düzeltme:21.06.2017 Kabul:23.06.2017

\section{Giriş}

Ülkemizde kadın cinayetleri, kadına yönelik şiddetin vardığı son nokta olarak, giderek artan bir gündem oluşturmaktadır. Yapılan araştırmalar kadınların aile yaşamlarında en çok eşlerinin veya yakın ilişki içerisinde olduğu erkeklerin fiziksel şiddetine maruz kaldığını göstermek- 
tedir. Kadın olduğu için şiddete uğruyor olmak toplumsal cinsiyet algısı ile açıklanabilir bir olgu olarak karşımıza çıkmaktadır. "Toplumsal cinsiyet" kadın ve erkek olmaya ait özelliklerin kültürel olarak nasıl algılandığı ile ilgili bir kavramdır. Kadınlık ve erkeklik algısı o toplum içinde konum rol ve görevlerin belirlenmesi açısından önemlidir.

Bu çalışmada kadın cinayetlerinde ön planda karşımıza çıkan ve toplumsal cinsiyet algısından güç aldığı düşünülen "sahip olma duygusu”, Fromm'un "olmak" ve "sahip olmak" kavramları ile açıklanmaya çalışılmıştır.

\section{Yöntem}

Bu gözden geçirme çalışmasında kadın cinayetleri ve nedenleri konusunda yazılmış makale, kitap ve tezlerden, istatistik veriler için de Kadın Cinayetlerini Durduracağız Platformu'nun 2017 yılına ilişkin verilerinden yararlanılmıştır. Özellikle aranan anahtar kelimeler "Kadın cinayetleri", "Sahip olma güdüsü" ve "Toplumsal cinsiyet" olmuştur. Alan indekslerinde yer alan hakemli dergilerde, 2000 yılı ve sonrasında yayınlanmış makaleler tercih edilmiştir.

\section{Nedensel bağlamda kadın cinayetleri}

Kadın cinayetleri kavramı kadınların, toplumsal rolleriyle bağlantılı nedenlerle öldürülmeleri anlamında kullanılmaktadır. Çalışmalar genellikle, erkeklerin otoritelerine veya statülerine yönelik tehdit algıladıkları zaman şiddete başvurduklarını göstermektedir (1). Caputi ve Russel, nedensel bir yaklaşımla kadın cinayetlerini tanımlarken; erkeklerin "kadını küçümseme, nefret, ya da kadına sahip olma duygusu" gibi nedenlerle kadın cinayetlerini işlediklerini belirtmişlerdir (2). Umut Vakfı "Kadın Cinayetleri Haritası" çalışmasında, 2015 yılında Türkiye'de basına yansiyan 309'u silahlı, toplam 414 kadın cinayetinden söz etmektedir. Aynı çalışmada 2016 yılının ilk ayında 40 kadın cinayeti işlendiği de eklenmiştir (3). Kadın cinayetleri platformu, 2016 yılının ilk altı ayında 153 , yedinci ayında 17 kadının cinayet nedeniyle kaybedildiğini bildirmektedir (4).

Cinsel partnerin veya yakın ilişkide olunan kadınların öldürülmesi ile sonuçlanan olaylarda failin temel nedeni genellikle terk edilmek olmaktadır. Ülkemizde kadın cinayetlerinin büyük çoğunluğu eşinden boşanmak veya terk etmek isteyen kadınlara karşı işlenmektedir. Eşini öldüren erkeklerin önemli bir bölümü de kıskançlık veya namus adına cinayet işlemektedirler (5)

Uğurlu ve Akbaş namus adına kadına şiddeti inceledikleri makalede kültürel bir bakış açısıyla, kadın üzerinden tanımlanan namus kavramına odaklanmışlardır. Diğer namus kültürlerinde olduğu gibi Türkiye'de de namus sistemi ailelerinin namusunu korumak için hem erkek hem de kadınları sorumlu tutmaktadır. Ancak, kadının her türlü davranışı erkeğin namusunun da belirleyicisidir. $\mathrm{Bu}$ açıdan kadının özellikle karşı cinsle olan davranışlarını kontrol altında tutmak ve onların namusunu korumak erkekler için bir görev niteliğindedir. Namusa gelecek herhangi bir tehdit veya kadının namusundan dolayı aşağılanma erkeğin aktif olarak bir meseleyi çözmesini gerektirmektedir (6).

Namus kültürlerinde namus, diğerlerinin değerlendirmesiyle önem kazandığından namusu zedeleyecek herhangi bir hareket kızgınlık, utanma ve aşağılanma gibi olumsuz duyguları uyandırır. $\mathrm{Bu}$ durumda namusun geri kazanılması ve yeniden yapılandırılması için bir onarım gerekir (6).

Namusunu korumadığı düşünülen kadına uygulanan en aşırı şiddet türü namus cinayetidir. Birleşmiş Milletler Nüfus Fonu'nun 2000 yılı UNFPA raporuna göre, tüm dünyada her yıl 5000'den fazla kadın namus nedeniyle kendi aile bireyleri tarafından öldürülmektedir. Raporda bu tür cinayetlerin Müslüman ülkelerde yaygın olmakla birlikte, bu ülkelerle sınırlı kalmadığı da ifade edilmektedir. Türkiye İnsan Hakları Başkanlığı'nın 2008 yılı Töre ve Namus Cinayetleri Raporuna göre 2003 ve 2007 yılları arasında 1148 kişi namus adına öldürülmüştür. Bu öldürülenlerin yarısına yakını kocaları tarafından öldürülen kadınlardır. UNFPA 2005 yılı raporunda Türkiye'nin tüm bölgelerde yapılan araştırmaya cevap verenler arasında; namus kavramını kadın, kadın cinselliği ve kadının kontrolü ile bağdaştırma yönünde kuvvetli bir eğilim ifade edilmiştir. Aynı raporda en yaygın namus anlayışının, kadınların hayatına sıkı bir kontrol getirerek ve aile erkeklerine onları bir mal gibi kullanma hakkı vererek kadınların ezilmesine de ortam sağlayan bir anlayıştan söz edilmiştir (7).

Namusuna zarar geldiği düşünülen erkek bu zarar1 onarmak üzere saldırgan davranışlarla tepki vermesi gerektiğinde stres yaşayabilir. Namusunun kirlendiğine dair toplumsal algı temizlenmezse toplumun ona atfedeceği olumsuzluklarla baş etmek daha da güçtür. Namus kültürlerinde gerek aile üyeleri, sosyal çevre, ataerkillik, gerekse erkeklik algısı ve hegemonik erkekliğin erkek üzerindeki baskısı, onun bu durumdan sorumlu gördüğü kadına şiddet uygulaması için referans olabilir (6).

Bağlı ve Özensel, namus cinayeti işleyip hapishaneye giren kişilerin depresyon, anksiyete, paranoya ve obsesifkompülsif psikolojik sorunları olmadığını göstermişlerdir. Mahkumların \% 47.9'u işledikleri cinayet için pişmanlık duymamaktadır. \% 41.1'i aynı durumda kalsalar yine cinayet işleyeceklerini belirtmektedir. \% 4.2'i hapse girmemek adına namuslarına leke süren kadını intihara 
zorlayacaklarını belirtmişlerdir. Sadece \% 37.9’u aynı durumda kalsalar bu suçu işlemeyeceklerini rapor etmişlerdir (8). Adli Tıp Kurumu Gözlem İhtisas Dairesi kayıtlarına göre, 1987-1998 yılları arasında Türkiye'de kadın cinayeti işleyenlerin \%74.7'sinin cezai sorumluluğunun tam olduğu görülmüştür (5).

\subsection{Hegemonik Erkeklik Kavramı}

"Hegemonik Erkeklik" kavramı şiddetin araştırılmasında kullanılan pek çok kavramdan biridir. Bu kavram aile içi şiddet bağlamında duygulanım ve güdülenmeyi anlamada yardımcı olabilir. Connell, kadın üzerine erkek baskınlığını destekleyen hegemonik (baskın) erkekliğin kadına uygulanan şiddet ile ilişkili olduğunu ifade etmiştir. Hegemonik erkeklik toplumsal arka planı olan bir kavramdır. Connell'ın geliştirdiği "hegemonik erkeklik" kavramı, ataerkil toplumsal yapıyla birlikte kültürel öğeleri de içererek, erkekliğin kuruluşu ve sürdürülmesiyle ilgili önemli bir çerçeve sunar (9). Hegemonik erkeklik kavramıyla, kaynağını ataerkil yapıdan alan cinsiyet düzeniyle birlikte, sınıf ilişkilerine ve kültürel dinamiklere de vurgu yapar. Kadınlar üzerinde kurulan hiyerarşinin yanı sıra, erkekler arasında kurulan hiyerarşiyi de gözler önüne serer. Burada amaç, kadının baskı altında tutulmasını sağlayacak bir erkekliğin yaratılarak, ataerkil idealin sürdürülebilmesini sağlamaktır (10).

Uğurlu, toplumsal erkek rollerini karşılamaya çalışan erkeklerin bu rollerle çelişen bir durum olduğunda düşük benlik saygısı, güvensizlik ve kızgınlıkta artış gibi psikolojik sorunlar yaşayabildiklerini ifade etmiştir. Aynı çalışmada (Malamuth, Linz, Heavey, Barnes ve Acker, 1995 ’ten alıntı ile) erkekler bu tür geleneksel hegemonik erkek rollerini yerine getiremediği zaman stres hissederler denmiştir (6).

USAK'ın Türkiye'de Kadına Yönelik Şiddet araştırmasında belirtildiği gibi; kadına yönelik şiddet, sadece kurban ve saldırgan arasındaki zorlayıcı iktidar ilişkileri ile değil, toplumsal cinsiyete dayalı şiddete katkıda bulunan sosyal ve siyasal iktidar sistemleriyle de ilgilidir. Boşanmış ya da ayrılmak isteyen kadınların daha fazla şiddete uğruyor olmalarının baş edilemeyen bir kontrol duygusu ile ilişkilendirildiği ve bunun da toplumsal eşitsizliklerden kaynaklandığı ifade edilmektedir. Bu nedenledir ki aynı raporda; kadına yönelik şiddetle mücadelede kadın-erkek eşitsizliğinin her alanda ortadan kalkacağı bir "zihinsel dönüşüm” den söz edilmektedir (11).

Dünya Sağlık Örgütü, kadına yönelik şiddeti öncelikli bir sağlık sorunu olarak değerlendiren çalışmasında (12), kadına yönelik şiddetin önlenmesinde erkeklerin sürecin bir parçası olabileceğini gösteren somut örnekler sunmuştur.

\section{2. "Sahip Olmak" ya da "Olmak"}

Fromm, mala, üne, bilgiye, insana "sahip olmayı" onları ele geçirmek, onlar üzerinde hakimiyet kurmak ve dilediği şekilde onları kullanma hakkı olarak tanımlamaktadır. Sahip olmaya karşıt olarak ileri sürdüğü kavram ise “olmak”tır. Olmak, her şeyi kendi bütünlüğü ve gelişimi içinde sevmek demektir (13).

Sahip olmak güdüsü ile başlayıp devam eden ilişkiler, bir kendine mal ediş sürecini ifade etmektedir. $\mathrm{Bu}$ aynı zamanda sahip olunanı kaybetme korkusu ve onu kendi benliğini bütünleyici bir nesne olarak algılamayı ifade eder.

Kişilik "olmak" tarafından belirleniyorsa, sahip olunan şeyler kaybedildiğinde kişiliğin yıkılması tehlikesi de doğmaz. Kişi odak noktasını ve davranışlarımı yönlendiren güdüleri, kendi içinde bulur. Sahip olma, sahip olduğu nesneler üzerinde hak sahibi olma düşüncesi, sahip olunanın, ne pahasına olursa olsun, korunmasını da beraberinde getirir. Sahip olunanın kaybedilmesi kişilik bütünlüğü için bir tehdit olarak algılanır.

Sahip olmak ve sahip olunan üzerinde egemenlik sahibi olmak kültürel değerlerle de beslendiğinde kültürel ve sosyal meşruluk kazanmaktadır. "Kız isteme", "kad1nın namusunun erkeğin namusu haline gelmesi”, "ya benimsin ya toprağın” gibi sosyal ön kabuller de meşrulaşmaya zemin hazırlamaktadır.

Fromm'un "olmak" kavramı insancıl ve varoluşçu kuramlarda da "kendini gerçekleştirme" olarak karşı11ğını bulmaktadır. İnsancıl kuramlarda kendini gerçekleştirme, psikolojik olarak tam sağlıklı insanı tanımlar. Rogers potansiyelini tam kullanan, kendini gerçekleştirmiş insanı değer koşullarına sahip kişi olarak tanımlar. Böyle bir kişi koşulsuz-olumlu özsaygıya sahip, başkalarının "meli-malı" ları yerine kendi organizmik değer verme süreçlerini ön planda tutan bir yapıya sahiptir $(14,15)$.

Ayrılığı kabullenmeyen yapı, çeşitli nedenlerle karşımıza çıkabileceği gibi, bu nedenlerden nesne ilişkileri ve ayrılma-bağlanma süreçleri önemli bir alanı oluşturmaktadır. "Sahip olma” güdüsü bu çerçevede değerlendirilebileceği gibi, bu değerlendirme sosyal ve kültürel bakış açısı ile de desteklenebilir. Nesne ilişkileri kuramına göre kendilik ve nesne dünyası erken duygusal deneyimler ve etkileşimlere bağlı olarak oluşur (16).

Bowlby>e göre çocuğun sağlıklı psikolojik gelişimi anne ve çocuk arasında kurulan güvenli bağlanma ilişkisine bağlıdır. Ainsworth de bebek ile anne arasında oluşan bağlanma stilinin çocuğun psikolojik gelişiminde ciddi bir öneme sahip olduğunu belirtmiştir. Güvenli bağlanma annenin sicak, duyarlı, bebeğin gereksinimlerini gidermeye hazır ve bağlanılabilir olma özelliklerini taş1- 
masıyla ilgili olup, duygusal sağlığın bir kaynağı olarak görülür. Çocuğa «ötekinin» ihtiyaç duyduğunda onun için orada hazır olacağı ile ilgili güven verir ki, bu da onun yetişkin yaşamında doyurucu ilişkiler kurma kapasitesine zemin oluşturur (17).

Erişkin hayatta da bu bağlanma tarzlarının uzantılarını gözlemleyebiliriz. Örneğin kararsız bağlanma tarzına sahip kişiler annelerinden öğrendikleri tutarsız ilişki kurma tarzını ilerideki ilişkilerinde de kullanırlar. Yapılan araştırmalar kaygılı/kararsız bağlanma tarzına sahip kişilerin ikili ilişkilerde aşırı uçlarda, aşırı kıskançlık ve tutku içeren, takıntılı düşüncelerle dolu, manevi benzeşme ve birleşme talep eden ilişkilerde yer aldıklarını ortaya çıkarmıştır

Tüzün ve Sayar'ın, aktardıklarına göre; bağlanma ve sahip olma ilişkileri içinde kültürden kaynaklanan destekleri de unutmamak gerekir (17). Türkiye'de kadınla ilgili toplumsal algiyı yansitan temel kavram "namus" olmaktadır. Bu kavram kadınları bağımsız bireylerden çok mensubu oldukları gruba ait bireyler olarak görülmelerine neden olmaktadır. Kadının her türlü davranışından kendini doğrudan sorumlu gören grubun erkek üyeleri de kendilerini hem kadını savunmakla hem toplumsal normlara karşı davranan kadınları cezalandırmakla yükümlü görmektedir. Bu alg1 ve algıdan doğan "görev" bilincinin erkeğin "sahip olma" dürtüsünü geliştirici bir işlevi bulunmaktadır. "Sahibi olduğu" kadına şiddet uyguluyor olmak ve hatta onu öldürmek için tamamen kendi dışında nedenleri vardır. Meselenin bu kadar dışsallaştırılmış olması ve adeta yüceltilmesi kadın cinayetlerinin kişisel meşruiyet zeminini hazırlamaktadır görüşündeyiz.

Dobash ve Dobash, kadınlara yönelik erkek şiddetinin nedenlerini şöyle sınıflandırmışlardır: (18)

- Erkeklerin kadınları başkaları ile paylaşmak istememesinden kaynaklanan kıskançlık duygusu,

- Erkeklerin özellikle aile içerisinde kadınlara atfedilen görevlere ilişkin beklentileri,

- Erkeklerin kadınların yaptıkları 'yanlış' davranışlardan dolayı onları cezalandırma hakkını kendilerinde görmeleri

- Erkeklerin kadınlar üzerinde otorite kurma ve toplumsal beklentilerin önemi

Kadın Cinayetlerini Durduracağız Platformu 2017 Şubat ayı kadın cinayetleri raporunda kadınların erkekler tarafindan öldürülme nedenleri gösterilmiştir (4).
Tablo 1. 2017 Şubat Ayı kadın cinayetleri nedenleri

\begin{tabular}{|l|c|}
\hline Neden & $\%$ \\
\hline Tespit edilemeyen & 37 \\
\hline Şüpheli ölüm & 27 \\
\hline Kendi hayatına dair karar alma & 20 \\
\hline İlişkiyi sonlandırma & 10 \\
\hline Evliliği sonlandırma & 6 \\
\hline
\end{tabular}

Tespit edilemeyen nedenler, olayların çok yeni ve henüz soruşturma aşamasında olması nedeniyle fazla gibi gözükmekle birlikte; hükümler kesinleştiğinde bu grubun diğer gruplar arasında dağılacağı düşünüldüğünde evliliği sonlandırma, kendi hayatına dair karar alma gibi özerkliğe ilişkin nedenlerin ilk sıralarda olduğu görülmektedir. Öldürülen kadınların \%36'sı boşanmak, kendi hayatına dair kararlar almak veya ilişkiyi sonlandırmak istiyordu. Bu sonucu destekler nitelikte pek çok çalışma ve istatistik bulunmaktadır. Bu nedenler içindeki temel nokta "sahip olunanı" kaybetme korkusu olarak değerlendirilebilir. $\mathrm{Bu}$ vazgeçilmezliğin öldürme noktasına gelmesi erkeğin toplumsal otoritesini de yitirmesi olarak algılanmaktadır. Terkedilme olasılığının söz konusu olduğunu hissettiğinde erkek, kadını ve hatta çocuklarını öldürebilmektedir. Tüm bu olgularda genel olarak erkeklerin o noktaya kadar zaten kadınları istismar ettikleri de bilinmektedir.

Tablo 2. Cinayet aleti

\begin{tabular}{|l|c|}
\hline Cinayet aleti & $\%$ \\
\hline Ateşli silah & 47 \\
\hline Tespit edilemeyen & 24 \\
\hline Kesici alet & 23 \\
\hline Darp & 3 \\
\hline Zehirleme & 3 \\
\hline
\end{tabular}

Ateşli silahların elde edilmesindeki kolaylık, bu noktada tekrar vurgulanmalıdır.

Kadına karşı şiddete başvuran erkekler üzerinde kapsamlı araştırmalar yapılmıştır. Bu erkeklerin çoğunda aşırı güvensizlik duygusu göze çarpmaktadır. Narsistik yaralanma eğilimleri çok fazladır. Aşırı bağımlıdırlar. En küçük bir ayrılma, boşanma tehdidi bu erkekleri paniğe sokar. Kendi özgüvenini kazanamamış, bağımlı kişilik yapısı gösteren erkekler çok kıskanç davranarak, kadının güven kazanmasına izin vermezler (19). 
Avşar'ın Türk'ten yaptığı bir alıntıyla belirttiği gibi (2015: 97-98), boşanma fikri, erkeğin iktidarına bir başkaldırı ya da onun hakimiyet alanından bir kopuşa, onun iktidarında bir zayıflamaya işaret ediyor gibi gözükmektedir. Ancak aslında söz konusu olan, eril tahakkümün ya da hegemonik erkeklik pratiklerinin bir başka araçsallık üzerinden gerçekleştirilmesidir (20). Bir eril değer olarak burada şiddet "kadınına sahip çıkmak" fikrinin uç noktasidır.

Erkeklerde, aldatılmış olma veya bunun şüphesi bile eşlerini öldürmüş olmada önemli bir güdülenme olarak karşımıza çıkmaktadır. Eşi tarafından artık tercih edilmiyor olmak veya bunun şüphesi bile, eşini öldürmeye kadar varabilen bir kin ve öfke yaratabilmektedir. Eşin bir başkası ile ilişki kurmasını kendi namusu ve şerefi olarak gören bir anlayış, ancak patolojik bir sahiplenme duygusu veya kişilik yapısındaki bozukluklar ile açıklanabilir. Kültür faktörü ile toplumsal yönden de desteklenen bu anlayış aile birliğine bir yarar sağlamadığı gibi, aile içi şiddetin de çoğu kez nedeni olmaktadır.

Eşini öldüren kadın ve erkekler üzerinde yapılan bir çalışmada (5), erkeklerin çoğunluğu, fiziksel şiddet uyguladıkları eşleri boşanmak istediğinde veya kendilerini terk ettiğinde, buna şiddetle karşı çıktığı üzerinde durulmuştur. Aynı çalışmada eşlerini öldüren kadınların en önemli gerekçesi bu kadınların şiddete maruz kalması (\%56.7) olarak bildirilmiştir. Kıskançlık, kıskançl1k şüphesi ve namus nedeniyle eş öldürme erkeklerde $\% 47.1$ olarak saptanırken; kadınlarda bu oran (\%6.7) olarak bulunmuştur. Bu noktada toplumsal cinsiyet algisından referans alan, patolojik bir bağımlılık ilişkisinden ve bağımlı kişilik yapısından söz etmek de mümkündür.

Çalışmalar genellikle, erkeğin erkekliğinin hiçe say1ldığı veya sorgulandığ 1 veya erkeklerin otoritelerine veya statülerine yönelik tehdit algıladıkları zaman şiddete başvurduklarını göstermektedir. Burada da sahip olunan şey otoritedir. Söz edilen eril otorite toplumsal kabul ve desteklerle birlikte vazgeçilmez bir nesneye dönüşmektedir.

Eril otorite erkeğin benliğini oluşturan temel öğe olarak algılanmaktaysa, karşı gelinmesi tamamen benliğe yapılmış bir saldırı olarak algılanmaktadır. Hele artık tercih edilmediği veya kendisinden ayrılmak istediği için eşini öldürenlerle bağlanma süreçleri açısından yapılacak araştırmalarda önemli sonuçlara varılacağ yiz. Ayrıca sosyal ve ekonomik yapılanma içinde sahip olmak, satın almak odaklı dayatmaların "sahip olma" güdüsünü geliştirdiği ve temelde hatalı bir örgütlenme söz konusu olduğunda, sahip olunan nesnenin ne pahasina olursa olsun kaybedilmemesi gerektiği çarpık düşüncesi ortaya çıkmaktadır. Kadının sahip olunan ve kendisinden ve namusundan sorumlu olunan bir nesne olarak alg1lanması onu dilediği gibi kullanma ve gerektiğinde de ortadan kaldırma hakkını beraberinde getirmektedir. Bu toplumsal algının değişmesi ancak uzun süreli ve sistemli yaygın "olmak" temelli eğitimler ile mümkündür.

\section{Sonuç ve Öneriler}

- Bireylerin namusun cinsellikle ilişkisine odaklanması yerine bireye saygı, kadın-erkek eşitliği ve genel olarak dürüstlük, doğruluk, onur ve sayg1 olgularına odaklanması sağlanmaya çalışılmalıdır.

- Namus olgusunun bireyin kendisine ait bir değer olduğu ve bu değerlerin adalet duygusu, dürüstlük gibi evrensel nitelikler taşıdığı,

- Fromm'un “olmak” kavramının kazanılması doğrultusunda bir eğitim anlayışına yönelik çalışmalar ve programlar

- Nesneye sahip olmak ve birey olmak arasındaki ilişkiyi değerlendirebilme konusunda farkındalık kazandırıcı etkinlikler

- Toplumu oluşturan bireylerin kendilik değerleri ve kendilik gelişimlerini destekleyici eğitim programları

$\mathrm{Bu}$ amaçla; eğitim-öğretim sürecinde müfredat programları düzenlenirken cinsiyetçi yaklaşımlara yer verilmemesi, eril otorite kavramıyla bütünleşmiş bir benlik algısının dışında, üretken yönelime sahip bireyler yetiştirme bilinciyle hareket edilmesi önemlidir. Fromm'a göre üretken yönelime sahip kişiler diğer insanları güç kullanarak değil, sevgi akıl ve model olma yoluyla etkilemeye çalışırlar. Burada sözü edilen sevgi; ilgi, sorumluluk, sayg1 ve bilgi ile karakterizedir.

Bu bağlamda, faillerle yürütülecek olan çalışmalar da önem kazanmaktadır. Örneğin; eşine şiddet uygulayan yükümlülere yönelik planlanacak grup çalışmalarının feminist ve bilişsel davranışçı yaklaşım temelinde yapılandırılması yararlı olacaktır. Dolayısıyla ele alınacak konular; ataerkil toplumsal yapı ve toplumsal cinsiyetin kadın ve erkek açısından nasıl yapılandırıldığını öğrenme, şiddet tanımları yapma, şiddet davranışının inkarı ile baş etme, şiddetin etki ve sonuçlarını fark etme, şiddetin öğrenilen ve değiştirilebilen bir davranış olduğunu kabul etme, şiddet davranışının değiştirilmesini isteme, öfke ile bağlantılı duygu ve düşüncelerin farkına varma, sağlıklı iletişim yöntemlerini öğrenme ve deneme, öfke kontrolü sağlayabilme ve yeni davranışları uygulama gibi temel konularda olmalıdır (21). 


\section{Kaynaklar}

1. Yarar B. Yakın İlişki İçinde Şiddeti Feminist Bakışla Yeniden Düşünmek. Şiddetin Cinsiyetli Yüzleri, Der. Betül Yarar. İstanbul: İstanbul Bilgi Üniversitesi Yayınları. 2015:1351

2. Caputi J, Russel DEH. Femicide: Speaking the unspeakable. MS.: The World of Women. 1990;(1)2:34-37

3. Kadın Cinayetlerinin Haritas1 [İnternet]. URL: http://blog. umut.org.tr/kadin-cinayetlerinin-haritasi.html Son Erişim: 26.09.2016

4. Kadın Cinayetlerini Durduracağız Platformu, Veriler [İnternet]. URL: https://kadincinayetlerinidurduracagiz.net/kategori/veriler Son Erişim: 06.03.2017

5. Kolburan G. Eş öldürme Olgularında Sosyal, Kültürel ve Psikolojik Faktörler. [Doktora Tezi] İstanbul: İstanbul Üniversitesi Adli Tip Enstitüsü, Sosyal Bilimler Ana Bilim Dalı; 1998.

6. Uğurlu SN, Akbaş G. Namus Kültürlerinde Namus ve Namus adına Kadına Şiddet: Sosyal Psikolojik Açıklamalar, Türk Psikoloji Yazıları, 2013;16(32):76-91

7. Kardam F. Türkiye'deki namus cinayetlerinin dinamikleri: Sonuç Raporu, Birleşmiş Milletler Nüfus Fonu, Nüfus Bilim derneği, Birleşmiş Milletler Kalkınma Programı (UNFPA), Ankara: 2005. p. 18

8. Bağlı M. Özensel E. Türkiye'de töre ve namus cinayetleri: Töre ve namus cinayeti işleyen kişiler üzerine sosyolojik bir araştırma. 1. Baskı. İstanbul: Destek Yayınevi; 2011. 232 pp.

9. Connell RW. On hegemonic masculinity and violence: Response to Jefferson and Hall. Theoretical criminology. 2002;6(1):89-99

10. Öztürk AB. Erkeklik ve kadına yönelik aile içi şiddet: eşine şiddet uygulayan erkekler. [Doktora Tezi] Ankara: Hacette- pe Üniversitesi, Sosyal Bilimler Enstitüsü, Sosyal Hizmet Anabilim Dali; 2014

11. Karal D ve Aydemir E. Türkiye'de Kadına Yönelik Şiddet, Uluslararası Stratejik Araştırmalar Kurumu (USAK) Raporlar1, No: 12-01. Ankara: 2012

12. World Health Organization (WHO). Violence against women: A priority health issue, Family and Reproductive Health. Geneva: 1997

13. Fromm E. Sahip olmak ya da olmak, Say Yayınları. İstanbul: 2016.

14. Maslow AH. Motivation and personality. New York: Longman; 2006

15. Rogers, CR. On Becoming a person: A psychotherapists view of psychotherapy. New York: Houghton Mifflin Company; 1995

16. Guntrip H. Schizoid Phenomena, Object Relations and the Self. Şizoid Görüngü, Nesne ilişkileri ve kendilik, Çev:

S.M. Tura. İstanbul: Metis Yayınlar1; 2013. p. 7-9

17. Tüzün O, Sayar K. Bağlanma Kuramı ve Psikopatoloji. Düşünen Adam. 2006;19(1):24-39.

18. Dobash RE ve Dobash PR. Women, Violence and Social Change. New York: Routledge; 2002.

19. Afşar ST. Türkiye'de Şiddetin "Kadın Yüzü". Sosyoloji Konferanslar1. 2015;52:715-753. DOI: 10.18368/IU/ sk.04297

20. Erten Y, Ardalı C. Saldırganlık, Şiddet ve Terörün Psikososyal Yapıları. Cogito. 1996;6-7:143-164

21. Çelik G. Eşine Şiddet Uygulayan Hükümlü Erkeklerin Özellikleri ve Toplumsal Cinsiyet Algıları [Doktora Tezi]. Ankara: Hacettepe Üniversitesi Sosyal Bilimler Enstitüsü Sosyal Hizmet Anabilim Dal1; 2015 